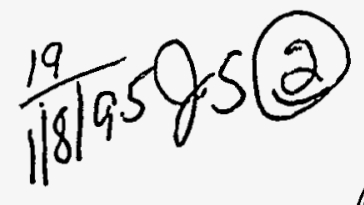

\title{
Environmental Guidance Regulatory Bulletin
}

July 31,1995

\section{National Oil and Hazardous Substances Pollution Contingency Plan}

\section{Revised Rule Issued}

\section{Effective Date: October 17, 1994}

\section{Introduction}

On September 15, 1994, at 59 FR 47384-47495, the Environmental Protection Agency promulgated a Final Rule revising 40 CFR Part 300*; the National Oil and Hazardous Substances Pollution Contingency Plan (NCP). One of the primary purposes of the revised NCP is to provide for efficient, coordinated, and effective action to minimize adverse impact from oil discharges and hazardous substance releases. The NCP is required by Section 105 of the Comprehensive Environmental Response, Compensation and Liability Act and Section 311 (c) (2) of the Clean Water Act. The NCP establishes an organizational structure and procedures for preparing for and responding to discharges of oil and releases of hazardous substances, pollutants, and contaminants under these two Acts. The Oil Pollution Act of 1990 (OPA) amends the existing provisions of the Clean Water Act (CWA) and creates major new authorities addressing oil, and to a lesser extent, hazardous substance spill response. These amendments to the CWA, in turn, require revision of the NCP. The OPA specifies a number of revisions to the NCP that enhance and expand upon the current framework, standards, and procedures for response. A Notice of Proposed Rulemaking on changes to the NCP was issued on October 22, 1993 (58 FR 54702). DOE solicited comments on the proposed rule from DOE program and field offices, and submitted those comments to EPA on December 20, 1993.

Specific aspects of the revisions to the NCP that affect DOE programs and facilities include:

Role of on-scene coordinators and remedial project managers

\section{Response operations}

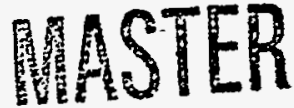 \\ -.}

\section{Federal agency participation}

Natural resource trustee responsibilities

The NCP and Executive Order 12580 (issued January 23, 1987) are the basis for DOE's implementation of the Comprehensive Environmental Response, Compensation, and Liability Act (CERCLA) at DOE facilities. The Executive Order delegates response authority to DOE from the President, while the NCP establishes EPA's procedures for implementing the CERCLA program and for responding to oil and hazardous substance discharges. DOE is required to carry out a number of key functions, including providing representatives to the National Response Team (NRT), the interagency organization responsible for planning for and responding to CERCLA releases and CWA discharges (see Definitions Table); acting as a natural resource trustee for land that DOE manages; performing natural resource damage assessments (NRDA); and assuming authority for certain response actions.

The NCP applies to:

1) discharges of oil into or on the navigable waters of the United States, the adjoining shorelines, the waters of the contiguous zone, the exclusive economic zone; or that may affect natural resources belonging to, appertaining to, or under the exclusive management authority of the United States.

2) releases into the environment of hazardous substances and pollutants or contaminants which may present an imminent and present danger to public health and welfare.

For a discussion of the provisions of Executive Order 12580 signed on January 23, 1987, please refer to the "Executive Order 12580: Superfund Implementation" Information Brief (EH-231-015/0593, May 1993).

The major revisions to the NCP reflect OPA revisions to CWA section 311. These changes increase Presidential authority to direct cleanup of oil spills and hazardous substance releases and augment preparedness and planning activities on the part of the federal government, as well as vessel and facility owners and operators. The OPA was enacted to strengthen the national response system and provide for better coordination of spill contingency planning among federal, state, and local authorities. Because Presidential authority for response to CERCLA oil and hazardous substance releases was delegated to DOE and other specified federal agencies under E.O. 12580, the revisions to the NCP do not substantially alter current DOE responsibilities in this area. The majority of changes to the NCP, resulting from the OPA, address responses to discharges, or threatened

*Also 40 CFR Part 9: "OMB Approvals Under the Paperwork Reduction Act," 1994, p. 183. 
discharges, of oil under CWA section 311. The language of the Final Rule uses the term "discharge," as defined by section 311(a)(2) of the CWA to refer to oil, and "releases," as defined under CERCLA, to refer to hazardous substance spills or releases.

\section{Organization for Response}

The NCP establishes a national response system for responding to discharges of oil and releases of hazardous substances. Figure $1 \mathrm{a}$ and $\mathrm{lb}$ of the Final Rule illustrate the roles of the national response system. DOE's request that EPA differentiate between responses to discharges of oil under the CWA and releases of hazardous substances under CERCLA was not incorporated in the revised rule. EPA believes these figures accurately reflect all categories of response without requiring additional explanation. DOE provides representation to the NRT, which is responsible for national response and preparedness activities, coordinating regional planning, and for providing policy guidance and support to the Regional Response Teams (RRTs): Under 40 CFR 300.120, federal agencies should also provide representation to the RRTs for the regions in which they have facilities. The regions, for the purposes of establishing RRT authority, correspond to existing EPA regions and U.S. Coast Guard (USCG) districts. Regions are further divided into areas which are managed by Area Committees.

\section{On-Scene Coordinators (OSC) and Remedial Project Managers (RPM)}

The OSC or RPM directs response efforts and coordinates all other efforts at the scene of the discharge of oil or release of hazardous substances. Revised 40 CFR 300.120 provides that the EPA or the USCG will predesignate OSCs' for all areas in each region.

The USCG shall provide OSCs for all oil discharges, including discharges from facilities or vessels under the jurisdiction of another federal agency, within or threatening the coastal zone. The USCG will also provide OSCs for removal of releases of hazardous substances except:

- where the release of hazardous substances, pollutants or contaminants is on, or the sole source of the release is from, any facility or vessel, under the jurisdiction, custody, or control of DOE, DOD, or any other federal . agency.

The EPA shall provide OSCs for discharges or releases into or threatening the inland zone except:

- where the release of hazardous substances, pollutants or contaminants is on, or the sole source of the release is from, any facility or vessel, under the jurisdiction, custody, or control of DOE, DOD, or any other federal -. agency.
DOE shall provide RPMs who are responsible for taking all response actions where the sole source of the release is from any facility or vessel under the jurisdiction, custody, or control of DOE.

In its comments on the proposed rule, DOE requested clarification in the final rule on EPA's responsibility to provide OSCs for oil discharges into or threatening the inland zone even where those discharges are from facilities or vessels under the jurisdiction of another federal agency. EPA declined to address this comment in the final rule. However, following an informal request for clarification, an Environmental Protection Specialist of the Emergency Response Division stated that EPA will provide OSCs for-all oil discharges in the inland zone.

In addition to providing OSCs or RPMs for hazardous substance releases from its facilities, DOE also provides advice and assistance to other OSCs or RPMs for emergency actions essential for the control of immediate radiological hazards.

Under revised 40 CFR 300.170 , federal agencies are responsible for reporting to the National Response Center releases of hażardous substances from facilities or vessels under their jurisdiction or control in accordance with section 103 of CERCLA. In addition, all federal agencies are now required to report discharges of oil that are in violation of section 311(b)(3) of the CWA from facilities or vessels under their jurisdiction or control to the National Response Center (NRC). Discharges of oil that meet the requirements of section 311(b) of the CWA are those that:

violate applicable water quality standards, or

cause a film or sheen upon or discoloration of the surface of the water or adjoining shorelines or cause a sludge or emulsion to be deposited beneath the surface of the water or upon the adjoining shorelines.

\section{Definitions}

The final rule amended the CWA definition of oil to reflect the OPA. In addition to the CWA definition of oil, the revised definition at 40 CFR 300.5 also states:

Oil, as defined by section 1001 of OPA, meañs oil of any kind or in any form, including, but not limited to, petroleum, fuel oil, sludge, oil refuse, and oil mixed with wastes other than dredge spoil, but does not include crude oil or any fraction thereof, which is specifically listed or designated as a hazardous substance under subparagraphs $(A)$ through $(F)$ of section 101(14) of CERCLA and which is subject to provisions of that act.

In response to the public comments on the proposed changes to the NCP, EPA received a request to address both 1) the appropriate response and funding for spills of statutorily defined "oil" which may exhibit, if tested, characteristics of a CERCLA "hazardous substance" in eithẹr its initial or 
weathered state; and 2) response funding where both "oil" and CERCLA "hazardous substances" may be involved in a discharge. The commenter had previously experienced difficulty where the USCG defined the discharge as CERCLA hazardous substance, while the EPA defined it as an oil. EPA declined to clarify the definition stating that the commenter's . concerns "touch on interagency policy issues that will be decided on a case-by-case basis between EPA and the USCG" (59 FR 47386). This definitional issue may become important to DOE because DOE will provide OSCs for releases of CERCLA hazardous substances that do not meet the definition of "oil" as defined at 40 CFR 300.5. Either the USCG or EPA, as appropriate, will provide OSCs for discharges of oil.

The revised NCP provides additional response actions and planning requirements for "worst case" discharges. DOE requested clarification of the term "worst case" discharge as it is used in the revised NCP. For example, section 311(a)(24) of the CWA does not specify whether "worst case" discharge applies only to oil or also to hazardous substances. EPA commented that, for the purposes of responding to a "worst case" discharge, the term applies only to discharges of oil. However, for planning purposes, CWA section 311(j)(5) requires tank vessel and facility response plans to address worst case discharges of oil or hazardous substances.

\section{Response operations}

Under revised 40 CFR 300.135 , the OSC is required to coordinate all response activities with the affected natural resource trustees, and for discharges of oil, shall consult with the affected trustees on the appropriate removal action to be taken. EPA has indicated that it does not interpret "consultation with" the affected trustees as a requirement for obtaining concurrence of the trustees "although such concurrence is highly desirable" (59 FR 47390).

Under 40 CFR $300.600(b)(3)$, DOE is designated a federal natural resource trustee for resources on, over, or under land it administers. Other federal agencies may also serve as natural resource trustees for resources found on DOE facilities. The lead federal administrative trustee for a response is designated on an incident-by-incident basis by the other trustees whose natural resources are affected by the incident. The lead federal administrative trustee facilitates communication between the OSC and other federal trustees during response operations and is responsible for applying to the OSC for non-monetary (personnel and equipment) federal response resources on behalf of all trustees.

Revised 40 CFR 300.305(e) states that the OSC and the trustees shall coordinate assessments, evaluations, investigations, and planning with respect to removal actions. The trustees are required to provide "timely" advice concerning recommended removal actions with regard to trustee resources that may potentially be affected. The trustees are also required to inform the $\mathrm{OSC}$ of activities related to natural resource damage assessment (NRDA) that may affect response. The trustees, through the lead federal trustee, will ensure that all data from NRDA activities that may support more effective operational decisions are provided to the OSC in a timely manner. Where circumstances permit, the OSC shall provide the trustees with non-monetary response . resources (personnel and equipment) for conducting damage assessments. In the response to comments on the proposed rule, EPA states that activities of the trustees and the OSC should be coordinated to prevent duplication of effort and promote effective use of resources.

\section{Planning and Preparedness}

CWA section $311(\mathrm{j})$, as revised by the OPA, requires the development of Area Committees (ACs) composed of representatives from federal, state and local agencies. The ACs are responsible for developing an Area Contingency Plan (ACP) which, when implemented, is adequate to remove a worst case discharge of oil under section 300.324 and to mitigate or prevent a substantial threat of such discharge from a vessel, offshore facility, or onshore facility operating in or near the area. An April 24, 1992 Federal Register notice (57 FR 15198) designates the initial areas. However, EPA has indicated that both area boundaries and ACPs are expected to change as the riational response system evolves. Changes to area boundaries will be published in the Federal Register.

Each ACP shall include a detailed annex containing a Fish and Wildlife Sensitive Environmental Plan (FWSEP) which shall address fish and wildlife resources and their habitat and shall include other areas considered sensitive environments. The FWSEP annex shall:

identify and establish priorities for fish and wildlife resources and their habitats and other important sensitive areas requiring protection from discharges;

provide a mechanism for timely identification of protection priorities;

identify potential environmental effects on fish and wildlife, their habitat, and other sensitive environments resulting from removal actions or countermeasures;

provide for pre-approval of application of specific countermeasures or removal actions which will minimize adverse impacts;

provide monitoring plans to evaluate the effectiveness of different countermeasures or removal actions;

identify and plan for the acquisition and utilization of necessary response capabilities for protection, rescue, and rehabilitation of fish and wildlife resources and habitat; and

identify appropriate federal and state agency contacts and alternatives responsible for coordination of fish and wildlife rescue and rehabilitation and protection of sensitive environments. 
Because of the requirement to pre-approve removal actions or countermeasures, DOE requested clarification of the application of the FWSEP annex; specifically requesting that the annex apply only to discharges of oil and not releases of hazardous substances under CERCLA. In its response, EPA stated that ACPs are currently required to only address discharges of oil; however, "planning for hazardous substance response is already being addressed in the area contingency planning process because individual Area Committees will consider planning for such releases, as appropriate"(59 FR 47397). Both Local Emergency Planning Committees (LEPCs) and State Emergency Response Committees (SERCs) may provide input to ACPs. The participation by these committees allows the ACPs to "effectively address hazardous substance planning issues, as necessary." The implication of this response appears to be that the extent to which ACPs address hazardous substances will be on a caseby-case basis and will be left to the Area Committee.

DOE also commented on the burden placed on federal agencies with control over extensive land and resources in the collection of fish and wildlife and sensitive environment information by the proposed rule. In the Final Rule, EPA clarified that although ACs, not facility owners, are responsible for identifying fish and wildlife resources and sensitive environments for inclusion in the ACP, "the facility owners and operators remain responsible for ensuring protection of sensitive environments in their proximity for inclusion in facility response plans" (59 FR 47397) until the geographicspecific annexes of the ACPs have been completed. The guidance for planning for these responsibilities on an interim basis is provided in a Federal Register notice published March 29, 1994 (59 ER 14713). However, EPA has reaffirmed the major role of the AC and has stated: "Ultimately, the Area Committee deliberations and their ACPs will specify information on fish, wildlife, and sensitive environments with which the facility plans must be consistent" (59 FR 47397).

The FWSEP annex is required to be prepared in consultation with NOAA, the U.S. Fish and Wildlife Service, and other interested natural resource management agencies. Trustee concurrence on the pre-approval of countermeasures and response actions is required.

DOE facilities have' several roles in the development of ACPs. Federal agency participation is required on the Area Committees which deyelop the ACPs and the FWSEPs. DOE must also cooperate with the AC to ensure that the Department adequately protects fish and wildlife and sensitive environments on, or in proximity to, its facilities. Once fish, wildlife and sensitive environments have been identified, DOE remains responsible for ensuring that those resources on, or in proximity to, its facilities are protected. Finally, as a natural resource trustee for resources on, in, or under land which it owns or manages, DOE concurrence on the preapproval of countermeasures and response actions is required.

\section{Designation of Federal Trustees}

As established by the NCP, natural resource trustees have the responsibility for protection of resources, assessment of damage, and restoration, rehabilitation, replacement, or acquisition of resources equivalent to those impacted by a CERCLA hazardous substance release or a discharge of oil. Preplanning and coordination for damage assessment activities are strongly encouraged at the regional and area levels, both during the area and regional planning and preparation, and during specific incidents where coordination with the OSC is required. In the Final Rule, EPA has revised 40 CFR 300.600 to clarify that trusteeship extends to the ecosystems supporting specific natural resources, and that habitat is included as part of the ecosystem.

\section{Definitions}

Coastal Zone means all United States waters subject to the tide, United States waters of Great Lakes, specified ports and harbors on inland rivers, waters of the contiguous zone, other waters of the high seas subject to the NCP, and the land surface or land substrata, ground waters, and ambient air proximal to those waters. The term delinentes an area of federal responsibility for response action. Precise boundaries are determined by EPA/USCG agreements and identified in federal regional contingency plans.

Discharge as defined by section 311(a)(2) of the CWA includes, but is not limited to, any spilling, leaking, pumping, pouring, emitting, emptying or dumping of oil, but excludes discharges in compliance with a permit under section 402 of the CWA. For the purposes of the NCP, discharge also means the substantial threat of discharge.

Inland Waters for the purposes of classifying the size of discharges, means those waters of the United States in the inland zone, waters of the Great lakes, and specified ports and harbors on inland rivers.

Inland Zone means of the environment inland of the coastal zone excluding the Great Lakes and specified ports and harbors on inland rivers. The term delineates an area of federal responsibility for response action. Precise boundaries are determined by EPA/USCG agreements and identified in federal regional contingency plans.

Release $\quad$ as defined by section 101(22) of CERCLA means any spilling, leaking, pumping, pouring, emitting, emptying, discharging, injecting, escaping, leaching. dumping, or disposing into the environment (see section 101(22) of CERCLA for exclusions). For the purposes of the NCP, it also means the threat of a release.

Worst Case Discharge

as defined by section 311 (a)(24) of the CWA means, in the case of a vessel, a discharge in adverse weather conditions of its entire cargo, and, in the case of an offshore facility, the largest foreseeable discharge in adverse weather conditions.

Please direct questions about the NCP Final Rule to: Katherine Nakata

DOE Office of Environmental Policy and Assistance RCRA/CERCLA Division

EH-413

1000 Independence Ave, SW

Washington, DC 20585

(202) 586-0801 
National Response System Concepts: Response

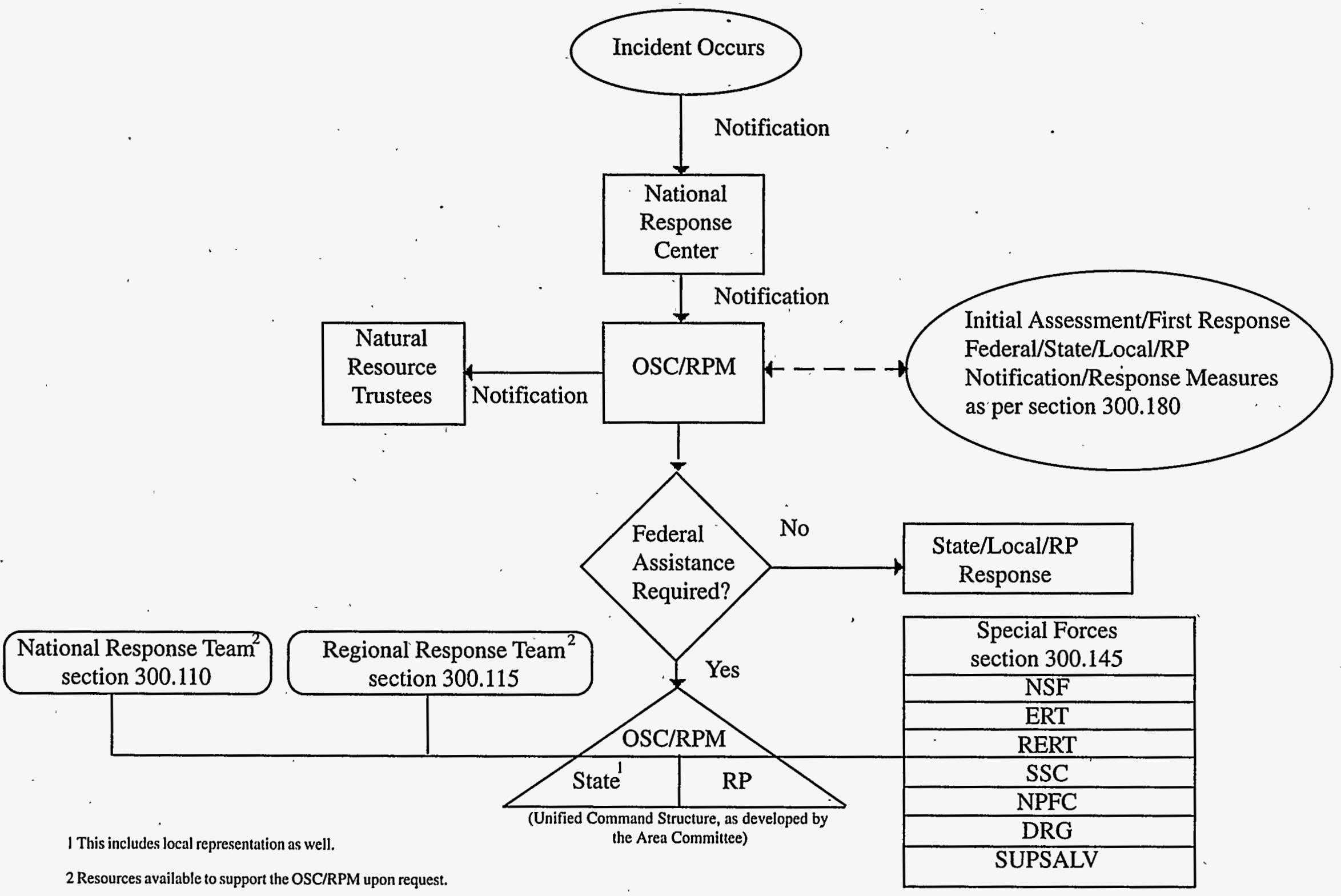


Figure $1 \mathrm{~b}$

\section{National Response System Concepts: Planning}

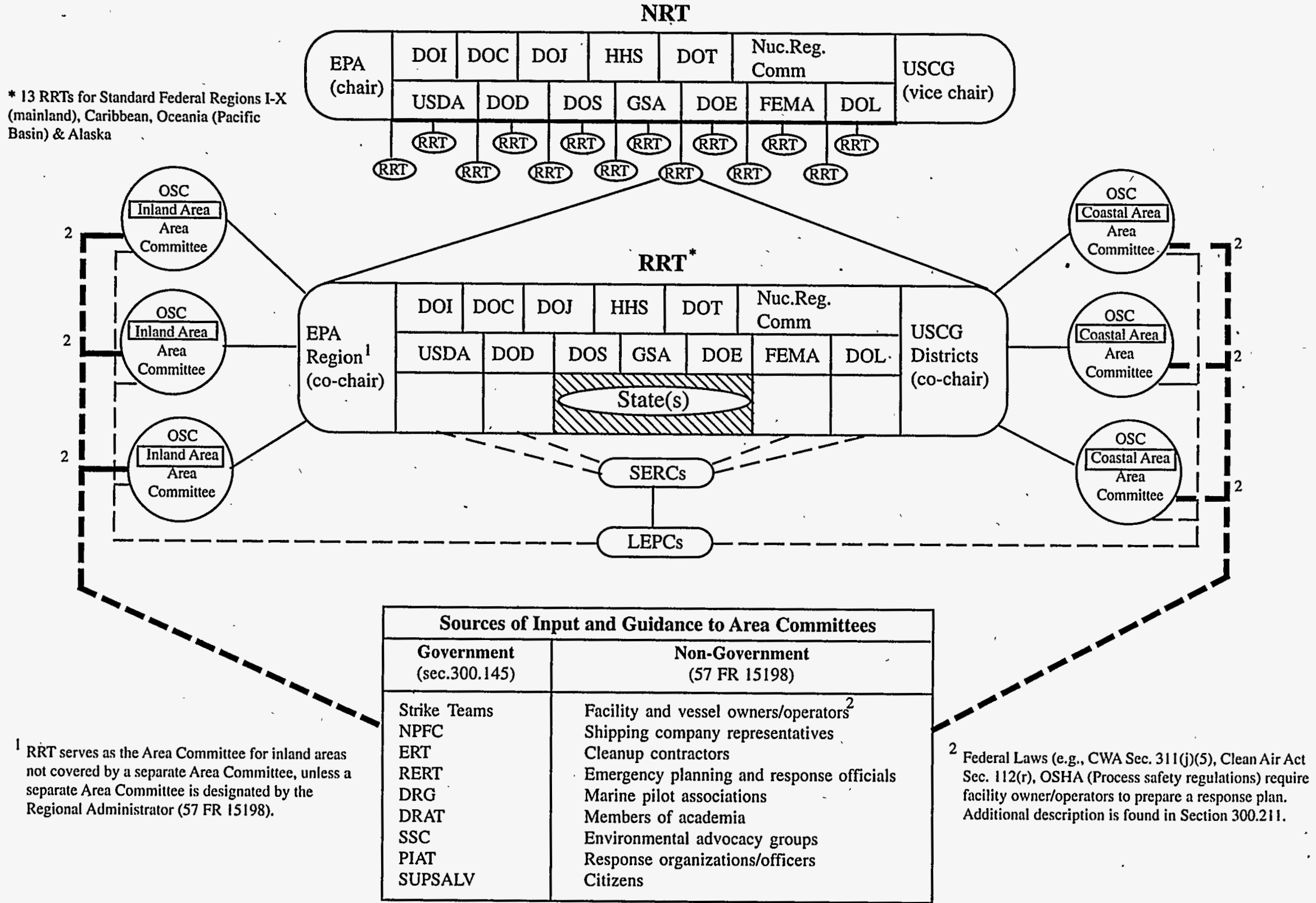

